\title{
Identidade Organizacional: um Caso de Manutenção, outro de Mudança
}

\author{
Clóvis L. Machado-da-Silva \\ Eros E. da Silva Nogueira
}

\section{RESUMO}

No presente trabalho procura-se verificar os fatores que delineiam a identidade de duas organizações brasileiras, Alfândega e TELEPAR, escolhidas intencionalmente. Parte-se do pressuposto de que a análise da identidade organizacional não se pode desvincular da visão de contexto institucional. Para tanto, procura-se avaliar o padrão de relacionamento entre os fatores que delineiam a identidade organizacional e o contexto institucional de referência, com base no estudo comparativo de casos. Mediante a utilização de múltiplas fontes de evidência, verifica-se a existência de valores, normas, expectativas de papéis e padrões reais de interação que, no conjunto, denotam a existência de estruturas sociais específicas, em termos do que é central, distintivo e duradouro para as pessoas que delas fazem parte. A análise dos dados permite concluir que os preceitos culturais do contexto institucional trazem em seu bojo conteúdos simbólicos compartilhados em sociedade, que afetam a formulação e a manutenção da identidade organizacional.

Palavras-chaves: identidade social; identidade organizacional; cultura organizacional; contexto institucional; mudança organizacional.

\begin{abstract}
This paper seeks to verify the factors which outline the identity of two Brazilian organizations, Alfândega and TELEPAR, which were intentionally chosen. It is presupposed that the analysis of organizational identity cannot be detached from the view of the institutional context. To this end, we have sought to evaluate the relationship pattern between the factors which determine organizational identity and the institutional reference context with a basis in comparative case study. By using multiple sources of evidence, it has been found that there exist values, rules, expectations of roles and real patterns of interaction which, all together, denote the existence of specific social structures in terms of that which is central, distinctive and enduring for the people who are part of them. The analysis of the data allows to conclude that cultural precepts of the institutional context carry in their wake symbolic contents which are shared in society which affect the formulation and maintenance of organizational identity.
\end{abstract}

Key words: social identity; organizational identity; organizational culture; institutional context; organizational change. 


\section{INTRODUÇÃO}

As pessoas configuram e estruturam a sua realidade como em um processo de representação. As solicitações da vida cotidiana requerem que se assuma um papel ativo para trazer à tona a realidade, atribuindo um significado e configurando um significante, apesar do hábito de se crer que a realidade é como as coisas são e se apresentam. $\mathrm{O}$ conceito de representação enfatiza o papel ativo que o indivíduo desempenha ao construir e reconstruir a sua visão de mundo.

Nessa linha de análise ganha destaque a visão representativa de cultura organizacional, que permite compreender as organizações como realidades socialmente construídas, existentes mais nas mentes dos seus membros do que nos seus elementos formais e objetivos. Estrutura organizacional, regras, políticas, objetivos, descrições de cargos e procedimentos operacionais padronizados desempenham funções relevantes nos sistemas de interpretação individual, grupal e organizacional. São utilizados como elementos de referência no modo pelo qual as pessoas pensam e dão sentido ao contexto e ao seu trabalho. Esses elementos nada mais são do que artefatos culturais para representar a realidade organizacional.

Assim, na perspectiva do processo de construção social da realidade, os relacionamentos diários na organização compõem o contexto onde os entendimentos podem ser construídos de modo a serem, ou não, convergentes. A formação dos grupos e os processos de liderança dependem da habilidade de se criar um senso compartilhado de realidade. Grupos coesos crescem em torno de entendimentos comuns; grupos fragmentados esposam visões de realidade múltiplas.

O raciocínio precedente leva a considerar que toda organização está em movimento (Hinings e Greenwood, 1989). Como tal, é dotada de uma trajetória consoante sua particular situação histórica e sua inserção em um contexto institucional. Mudança e estabilidade são, portanto, duas facetas de uma mesma dimensão que estão intimamente ligadas à noção de arquétipo organizacional: vinculação entre as estruturas e sistemas de uma organização com as idéias, crenças e valores subjacentes, notadamente do grupo com poder para disseminar as suas províncias de significados.

As estruturas e sistemas prescritos (papéis e responsabilidades, sistemas de decisão e de recursos humanos, e assim por diante) não são exaustivos, o que leva os membros da organização a suprirem lacunas ou a desconsiderarem, em 
maior ou menor grau, o formalmente estabelecido, mediante as interações cotidianas que, além do mais, propiciam a emergência de novos padrões de significados. As organizações constituem, portanto, um lugar privilegiado para o entendimento das relações entre as dimensões simbólica e estrutural.

Essas duas dimensões, mediadas pelas relações de poder, permitem que se compreenda a noção de ordem organizacional. A ordem organizacional, por sua vez, exerce papel relevante na edificação da ordem societária. A sociedade pode ser vista como natureza histórica, uma ordem em movimento, em que o equilíbrio é sempre instável, em face da sua constituição na ordem organizacional e inserção numa ordem maior, a ordem mundial. Nesse sentido, Chanlat (1992) sugere que o fenômeno social possa ser estudado em cinco níveis de análise: do indivíduo, das interações, da organização, da sociedade e mundial.

Sem descurar dos níveis de análise, é possível entender que uma cultura estabelece uma identidade, uma marca reconhecível quer pelos que dela participam, quer pelos que com ela interagem. Essa identidade corresponde a uma visão de mundo, a um modo particular de fazer as coisas, de interagir e de ser. Dessa maneira, a identidade organizacional pode ser considerada como resultante de uma representação compartilhada pelos membros de uma organização, em face daqueles com quem ela interage. Em conseqüência, a identidade organizacional pode ser vista como elemento-chave interpretativo do senso compartilhado de realidade.

A partir dessas considerações preliminares, procura-se, no presente artigo, analisar a identidade organizacional com base no exame de dois casos intencionalmente escolhidos: um de manutenção, outro de mudança. O caso de manutenção da identidade refere-se à Alfândega brasileira; já a TELEPAR - Telecomunicações do Paraná S/A (assim designada na época da pesquisa) configura-se como o caso de mudança de identidade. Para tanto, este trabalho está estruturado da seguinte forma: uma seção destinada a estabelecer o quadro de referência conceitual do estudo, onde se discutem, em especial, os conceitos de cultura e de identidade organizacional; outra em que se apresenta a situação em análise, com breves relatos tanto do caso da Alfândega como da TELEPAR. Por último, à guisa de conclusão, uma seção de considerações finais.

\section{Quadro Teórico de Referência}

O conceito de cultura tem sido utilizado em diversos contextos e com acentuadas diferenças de significado. Essa variação decorre da perspectiva adotada e 
do que se assume como essencial: crenças; pressupostos básicos; valores e práticas; ideologia; entendimentos significativos; programas coletivos da mente; e outros (Geertz, 1989; Schein, 1991; Alvesson e Berg, 1992; Sackmann, 1992; Trice e Beyer, 1993). Em comum, todas essas abordagens pressupõem que a cultura confere racionalidade ou significados compartilhados ao que poderia, de outra forma, ser considerado sem sentido. Garante, pois, condições de previsibilidade e de estabilidade ao conhecimento humano.

Smircich (1983) propõe uma tipologia que serve de referência para o entendimento das abordagens sobre cultura. A autora argumenta que o estudo da cultura vem sendo desenvolvido sobre dois enfoques distintos: a cultura como variável e a cultura como metáfora. No primeiro enfoque, considera-se que a organização tem uma cultura e a orientação fundamental é administrativista: enfatiza-se a possibilidade de seu gerenciamento para o alcance de altos padrões de desempenho organizacional. Já a cultura como metáfora é interpretada, essencialmente, como um contínuo e dinâmico processo de construção e reconstrução da realidade por meio da interação social, razão pela qual é a perspectiva adotada neste trabalho. Compreende as abordagens que consideram a organização como um modo de expressão da consciência humana, de suas idéias e aspectos simbólicos. Nessa visão, a organização não tem uma cultura mas é uma cultura. Os que seguem essa perspectiva geralmente adotam uma definição antropológica de cultura.

Entre os enfoques da cultura como metáfora interessam especificamente para este estudo o cognitivo e o simbólico. Tal interesse decorre da necessidade de entendimento da concepção e da ação dos indivíduos participantes do grupo, e dos que com ele interagem, a respeito dos valores e crenças que têm sobre o próprio grupo, que julgam que outros tenham sobre o grupo e que os suponham aceitos pela sociedade.

A abordagem cognitiva compreende cultura como um sistema de conhecimentos, de padrões de percepção, de crenças e de modelos de avaliação aprendidos que norteiam o modo de os indivíduos agirem. Já a abordagem simbólica referese a símbolos e significados compartilhados que resultam das interações sociais, em face da necessidade de interpretar a realidade e de estabelecer critérios orientadores para a ação. Nessa perspectiva, a análise organizacional focaliza a maneira como os indivíduos entendem as suas experiências e as situações em que convivem e como essas interpretações se relacionam com a ação.

O entendimento de que as organizações são, no mais das vezes, multiculturais vem predominando na literatura especializada (Martin, 1992; Trice e Beyer, 1993; Rodrigues, 1997). A maioria das organizações, exceto as muito pequenas, usualmente são constituídas por subculturas. Com base na análise das crenças e dos 
valores é possível distinguir essas subculturas da cultura abrangente da organização. Há muitos fatores que podem explicar o desenvolvimento e a existência de subculturas: campos específicos de conhecimento, segmentos ocupacionais, grupos demográficos, e assim por diante.

A ocupação, por exemplo, pode prover motivo e base para significativas e altamente organizadas subculturas que, muitas vezes, se estendem para além das fronteiras da organização. As ocupações definem papéis e atividades que os seus membros podem passar a considerar como de seu direito exclusivo. Ao longo do tempo, podem-se criar definições, valores e ideologias que auxiliam a pessoa a manter a sua identidade com a ocupação e a justificar as suas ações. Além disso, membros de uma mesma ocupação freqüentemente compartilham a consciência de constituírem uma categoria diferenciada das demais, apoiando-se uns nos outros, como ponto de referência. Podem desenvolver identidade a partir de suas atividades, compartilhando extensivas relações sociais e tornando-se etnocêntricos. As ocupações têm sido consideradas como fonte importante do surgimento de subculturas, compondo as denominadas comunidades ocupacionais. Os meios eletrônicos de comunicação, as mídias de massa, a interdependência de papéis, a tenuidade dos laços sociais e outros fatores propiciam que essas subculturas mantenham sua dinâmica interação e existência para além das fronteiras da organização (Alvesson e Berg, 1992; Trice e Beyer, 1993).

Em face do exposto, entende-se cultura organizacional como sendo o conjunto de crenças, valores, artefatos, práticas e significados concebidos, aprendidos e compartilhados pelos membros de uma organização. Tal conjunto propicia sentido e permite a interpretação da realidade. Como elementos para a identificação e a descrição da cultura, no contexto deste artigo, adotam-se valores e crenças, principalmente por serem os mais amplamente aceitos entre os autores consultados.

Os valores constituem concepções racionalizadas que expressam preferências por determinados cursos de ação em detrimento de outros teoricamente possíveis (Machado-da-Silva, Fonseca e Fernandes, 2000). Já as crenças podem ser definidas como componentes subjacentes, pressupostos básicos de como a realidade é ou se apresenta, que delineiam, juntamente com os valores, as opções dos indivíduos, servindo de fundamento à racionalização (Enz, 1988).

De acordo com Hatch (1997), a relação entre valores e crenças é interativa. De um lado, as crenças sustentam os valores, à medida que aquilo que as pessoas assumem como verdadeiro influencia o que valorizam. De outro, os valores podem dar origem a crenças na própria medida em que, reafirmados consistentemente em comportamentos bem-sucedidos, passam a ser incorporados gradativamente como verdade, passando à categoria de pressupostos subjacentes. 
Os membros de determinada cultura adotam valores e se ajustam às normas porque suas crenças fundamentais alimentam esses valores e normas. Por sua vez, os valores e as normas estimulam certas atividades e oferecem condições para a produção e a valorização de artefatos. Os artefatos culturais são, em última instância, extensões ou expressões dos elementos essenciais da cultura.

Machado-da-Silva, Fonseca e Fernandes (1999) propõem que a realização dos significados é mais do que mera passiva recepção. Os significados são construídos e reconstruídos ativamente, em modos indexados, refletidos e dotados de propósito. Ademais, Morgan (1996) focaliza o entendimento de que ação e símbolo são inseparáveis; toda ação tem um aspecto simbólico, significante e valorizado somente em termos da sua relação com outros símbolos que, mais do que causa do agir, se realizam por meio do agir.

Ao mesmo tempo que os valores e as crenças podem expressar-se por meio de artefatos, estes, por sua vez, são utilizados para inculcar novos valores e crenças ou para reforçar aqueles já existentes. Assim é que os artefatos e as normas são usados pelos membros de uma cultura para expressar a sua identidade e para formular e perseguir os seus propósitos.

\section{O Conceito de Identidade}

A par das diferenças de conceituação provindas das várias escolas nos domínios da psicologia e da psicanálise, na maioria delas parece haver concordância em que a identidade do indivíduo está relacionada com o sentido de unicidade pessoal e de continuidade histórica. A identidade pessoal seria um processo interno do indivíduo, mas que é influenciado pela cultura (Adler, 1957; Filloux, 1960; Allport, 1973; Freud, 1974, 1976; Erikson, 1976; Lacan, 1985; Jung, 1988; Freitag, 1991; Lyra, 1997). Ela seria um modo de expressão do self do indivíduo, que lhe permite ser reconhecido como diferente dos demais e, ao mesmo tempo, como similar aos membros de uma categoria ou classe.

A psicologia social tem entendido identidade como fenômeno social, resultante dos significados provenientes das interações mantidas pelo indivíduo na sua vida em coletividade. Como atributo sociocognitivo, a identidade não é inata nem exclusiva do indivíduo. Os grupos e as organizações também teriam identidade. De fato, por meio do processo de identificação, a identidade do indivíduo estaria relacionada estreitamente com a identidade dos grupos e organizações em que ele se insere. Além disso, a identidade também poderia ser entendida como tendo uma natureza reflexiva, o modo como a pessoa vê a si mesma seria o seu autoconceito. 
As diferenças entre psicologia individual e social seriam não essenciais, pois a primeira se concretiza no homem isolado, investigando os caminhos por meio dos quais tenta alcançar a satisfação dos seus instintos. Acontece que somente em circunstâncias excepcionais ele poderia prescindir das relações com seus semelhantes. Na vida anímica individual ele aparece sempre efetivamente integrado a outro, como modelo, objeto, auxiliar ou adversário; assim, a psicologia individual seria, ao mesmo tempo e desde o princípio, psicologia social em um sentido amplo (Freud, 1974).

Erikson (1976) estudou a noção de identidade, descrevendo-a como um sentimento subjetivo de revigorante uniformidade e continuidade, possuindo natureza pessoal e cultural. Para esse autor, a formação da identidade compreende o processo essencial no âmago do indivíduo e a inserção na cultura coletiva. Propõe que a formação da identidade é inseparável da evolução sociogenética, uma vez que somente dentro de um grupo definido ela pode existir. Vislumbra, contudo, que o indivíduo possa transcender a sua identidade e se tornar verdadeiramente individual e, ao mesmo tempo, situar-se além da individualidade. Haveria um nexo entre as imagens sociais e as forças organísmicas, entre identidade de grupo e identidade de ego, de ethos e ego.

\section{Identidade Social}

Ao adotar uma posição nem idealista nem positivista da possibilidade de se conhecer o indivíduo e a realidade, Pages et al. (1993) afirmam que o discurso informa ao mesmo tempo: (1) sobre uma realidade objetiva exterior e transcendente ao indivíduo, e (2) sobre seu universo mental. O discurso de cada indivíduo seria ao mesmo tempo coletivo e individual. Coletivo à medida que revela, de maneira exemplar, estruturas e relações entre fenômenos, presentes de diferentes formas nos outros indivíduos. Também seria coletivo pela complementaridade, ao invés de só pelas semelhanças, entre os diferentes discursos individuais. $\mathrm{O}$ caráter coletivo do discursos remeteria, necessariamente, ao conceito de estruturas: à existência postulada de relações entre fenômenos que operam transversalmente sobre toda a extensão do campo sociomental e a um corpo teórico de hipóteses sobre a natureza dessas relações .

Cabe aqui assinalar que os sistemas estruturais e simbólicos articulam as relações sociais no nível da sociedade (Holmer-Nadesan, 1996). A sociedade seria o espaço onde essas relações são exercidas, com suas características socioculturais comuns (tradições, língua) e especificidades sociopolíticas (estrutura de classe, organização política). Para tanto são utilizados símbolos coletivos, conceitos e valores, que conferem certa coesão à identidade social. Nesse contexto se desenrolam os conflitos, as tensões, as mudanças, as histórias (Dejours, 1992). A 
sociedade é domínio e condição do sentido e significado; ela invade o indivíduo, suas interações e criações. O ser humano é o ser socializado de determinada sociedade. O indivíduo é amoldado ao seu grupo - mediante gestos, ritos, atitudes, comportamentos e signos - para que possa ser aceito e reconhecido pelo grupo e para que possa atuar nesse grupo. Esse processo está na base da identidade e da alteridade, as duas faces da realidade identitária.

Para Berger e Luckman (1967) a identidade é elemento-chave da realidade subjetiva e se encontra em relação dialética com a sociedade. De um lado, a identidade seria formada, conservada e/ou remodelada por processos sociais, determinados pela estrutura social. De outro, ela reage sobre a estrutura social, procurando mantê-la ou modificá-la. As estruturas sociais históricas engendram tipos de identidade, elementos relativamente estáveis da realidade social objetiva, mas isso não significa a formulação de uma identidade coletiva.

Em suma, os níveis individual, interpessoal, organizacional e societário estão em constante interação. As relações de um nível para outro são complexas e interdependentes. $\mathrm{O}$ indivíduo se desenvolve e constrói a sua identidade em sua relação com o outro e, também, por sua inserção em contexto organizacional e social específico.

\section{Identidade Organizacional}

A identidade organizacional pode ser visualizada em diversas dimensões, de acordo com Caldas e Wood (1997). Pode resultar de sua imagem externa, isto é, da forma pela qual a organização é percebida por aqueles com quem ela interage, como, por exemplo, clientes e fornecedores (Engels, Blackwell, e Miniard, 1995). Pode decorrer, também, da autopercepção ou da auto-imagem, ou seja, da maneira como seus membros internos, especialmente seus dirigentes, a percebem de forma compartilhada. Pode representar o propósito existencial resultante da definição da razão de ser, da finalidade, missão ou propósito da organização.

No que concerne ao presente artigo, o conceito de identidade organizacional adotado é o proposto por Albert e Whetten (1985). Na visão desses autores, a identidade organizacional compreende o que é central, distintivo e duradouro na organização, com base nas crenças compartilhadas pelos seus membros. "O critério de centralidade aponta as características vistas como a essência da organização. O critério de distintividade aponta os elementos que distinguiriam uma organização das outras com as quais poderia ser comparada. O critério de continuidade temporal ressalta as características estáveis no tempo" (Albert e Whetten, 1985, p. 265). Os autores afirmam que esses três critérios atenderiam às condições de 
necessidade e de suficiência para definir identidade organizacional como conceito científico.

O critério que pretende estabelecer o caráter distintivo da identidade, embora não possa ser, do ponto de vista de Albert e Whetten (1985), uma propriedade mensurável, pode ser traduzido de diversas maneiras, tais como objetivos organizacionais estratégicos, missão, proposições ideológicas, valores, filosofia ou cultura específica. Esses autores argumentam, ainda, que os estudos sobre o tema precisariam considerar que as organizações podem não ter uma identidade unidimensional ou única; elas podem ser híbridas, compostas de múltiplos tipos. Compreendem, também, que em nível organizacional, possivelmente como se supõe ocorrer no nível dos indivíduos, a identidade organizacional é formulada e mantida por meio de interações, de forma análoga aos modelos propostos por Mead (1953) e Goffman (1985).

Nessa mesma linha de análise, Elsbach (1994) sublinha que a identidade de uma organização reflete seus atributos centrais e diferenciadores, incluindo os seus valores essenciais, modos de desempenho e de agir, e produtos. No nível dos indivíduos que participam da organização, a identidade organizacional é fruto do seu esquema cognitivo ou da sua percepção dos atributos essenciais e distintivos da organização, da sua situação e do seu posicionamento no contexto em comparação com outras organizações. O senso compartilhado de continuidade da organização pode estar amparado na percepção de continuidade proporcionada pelos discursos e narrativas que operam a estabilidade da ordem social ou grupal, inter-relacionados aos hábitos e aos recursos de comunicação (figuras conceituais, metáforas, signos e outros) adotados por eles (Alvesson, 1994).

Trabalhos mais recentes, também no âmbito da Psicologia Social, tratam a identidade organizacional como função da forma como a organização percebe a si mesma. Haveria, nesse enfoque, correlação entre identidade organizacional, autoconceito individual e imagem da organização (Dutton, Dukerich e Harquail, 1994). Já outros estudiosos discutem o conceito de identidade organizacional sob a ótica de imagem organizacional ou corporativa, ou seja, a sua imagem externa e a percepção dessa imagem externa (Alvesson e Berg, 1992).

Elsbach (1994) apresenta o ponto de vista de que é necessário distinguir entre dois tipos de percepção da identidade organizacional: (1) a identidade organizacional percebida pelos seus membros (aquilo que eles crêem serem os seus atributos centrais, distintivos e duradouros); (2) a sua identidade externa construída (aquilo que eles, os membros, pensam que aqueles que não pertencem à organização crêem serem esses atributos centrais, distintivos e duradouros). Os dois tipos de percepção estão relacionados com representações cognitivas mantidas pelos indivíduos, membros e não-membros da organização. 
Essa visão sugere alguns fatores que poderiam estar relacionados com o aumento da identificação organizacional. Primeiro, a distintividade dos valores e das práticas dessa organização em comparação com os de outras seria um importante fator que proporciona um entendimento de identidade única e singular. Essa distintividade poderia explicar, em parte, o zelo missionário de membros de organizações recém-criadas ou que esposam objetivos específicos e altamente valorizados pela coletividade. O segundo seria o prestígio que a afiliação proporcionaria, tendo em vista os mecanismos de comparação social, afetando a autoestima. Por último, a identificação organizacional ressaltaria a não-inclusão do indivíduo em outros grupos, sublinhando a homogeneidade dos que se sentem participantes e a separação ou segregação em relação aos não-semelhantes.

Assim, a identidade social seria um mecanismo cognitivo que tornaria possível o comportamento grupal. As definições situacionais e as autodefinições emergiriam por meio de interações simbólicas, em que os significados evolveriam das interações verbais e não-verbais dos indivíduos. O entendimento da singularidade da identidade de uma organização pode ser compartilhado não somente entre seus membros, mas por outros indivíduos e grupos que se relacionam com ela, como fornecedores, clientes e consultores, por exemplo.

Nesse sentido, Turner (1986), ao analisar os aspectos sociológicos do simbolismo organizacional, argumenta que os indivíduos também mantém uma concepção da sua própria identidade social, que é uma medida do seu próprio autoconceito, definida pela sua associação ou afiliação com grupos sociais. Acredita-se que, em nível cognitivo, as identidades sociais dos indivíduos são delineadas em termos de múltiplas e hierárquicas categorias, incluindo diversas bases de referência, tais como geração, idade, raça, ocupação, afiliações organizacionais. Assim, a percepção a respeito da identidade organizacional pode ter efeito direto sobre a percepção da própria identidade social.

Em face da relação entre identidade social e organizacional, os estudiosos vêm procurando avaliar a sua importância e extensão. As pessoas podem buscar identidades sociais mais positivas e aceitas, mediante associação com organizações que tenham identidade positiva (como se houvesse uma transferência dos atributos para a identidade social). O inverso também seria passível de análise: a ameaça à identidade organizacional ou do grupo pode constituir ameaça à identidade social.

Desse modo, a identidade organizacional pode ser compreendida como resultante dos esquemas cognitivos ou percepção a respeito dos atributos diferenciadores e essenciais da organização, incluindo o seu posicionamento no contexto (status) e as comparações relevantes com outros grupos ou organizações. Eventos externos e situações ambientais que refutem ou coloquem em questão essas características 
definidoras podem ser percebidos como ameaças à percepção dos membros em relação à identidade da organização da qual façam parte (Elsbach e Kramer, 1996; Gioia e Thomas, 1996)

Há vários elementos que vêm sendo usados para explicar que as organizações possuem identidades coletivas, resultantes das crenças que os seus participantes compartilham do que seja central, distintivo e duradouro para cada uma delas. Muitos estudiosos afirmam que é menos importante se esses elementos justificadores de singularidade são ou não são empiricamente válidos do que a evidência de que os membros se engajam intensamente nos processos de comunicação e mútua influência para formular ou manter uma identidade coletiva. Essas organizações articulam um conjunto de expressões culturais, tais como símbolos e rituais, cerimônias e histórias, que traduzem, comunicam e codificam padrões organizacionais compartilhados de entendimentos e comportamentos (Allaire e Firsirotu, 1984). Esse repertório de expressões culturais delineia e comunica a identidade coletiva da organização.

Ainda assim, nem sempre as pessoas estão conscientes desses atributos definidores da identidade organizacional, que podem permanecer subliminares para elas até que a identidade seja ameaçada ou desafiada (Albert e Whetten, 1985; Fiol, 1991). Muitas vezes alterações consideradas importantes no contexto ambiental, como as promovidas por novas normas que regulamentam o setor ou aquelas provocadas por redefinições de posicionamento estratégico entre concorrentes, podem desvelar ou tornar mais evidente a identidade coletiva da organização.

A identidade também pode tornar-se mais saliente, quando seus membros observam a eclosão de inconsistência entre ela e as estratégias da organização ou quando as ações individuais de seus membros contradizem a identidade ou a imagem da organização (Alvesson, 1994). Quando isso ocorre, as ações individuais ou coletivas interrompem o curso normal de funcionamento organizacional, levando os participantes a se questionarem sobre a finalidade e a natureza das suas atividades. Constituem momentos de revisão, aprofundamento e ampliação da consciência a respeito do que eles acreditam definir a organização; também e possivelmente são momentos para rever a magnitude da conexão que mantêm, individual e coletivamente, com a organização.

\section{A Situação em Estudo}

O referencial teórico brevemente delineado na seção precedente forneceu as bases para a análise dos casos da Alfândega brasileira e da TELEPAR. Como se 
poderá observar na seqüência deste artigo, os recursos conceituais desse quadro de referência permitiram verificar se os membros de cada uma das organizações objeto do estudo lhes atribuem razão de ser e propósito, imagem e atributos próprios e até que ponto esses aspectos podem estar contribuindo para um senso de existência e identidade organizacional compartilhados.

\section{Procedimentos Metodológicos}

A presente pesquisa caracteriza-se como estudo comparativo de casos, com múltiplas fontes de evidência. A abordagem metodológica, predominantemente descritivo-qualitativa, permitiu analisar, em cada organização, aspectos intersubjetivos, portanto compartilhados, tais como percepções, compreensão do contexto ambiental e organizacional, significados relevantes e a dinâmica das interações sociais de indivíduos e grupos. A investigação foi conduzida com base, em especial, nos discursos e nas práticas cotidianas, remetendo-os, sistematicamente, para o nível de análise organizacional.

Entrevistas semi-estruturadas com pessoas selecionadas, de acordo com critérios de amostragem intencional e estratificada casual, constituíram as fontes primárias de dados. No caso da Alfândega brasileira foram realizadas doze entrevistas, assim distribuídas: quatro com ex-dirigentes do Sistema Aduaneiro, três com dirigentes em atividade do nível estratégico e cinco com gerentes dos níveis regional e local. No que concerne à TELEPAR, foram entrevistados todos os sete dirigentes do nível estratégico e treze gerentes do nível tático, totalizando vinte entrevistas. As fontes secundárias compreenderam documentos internos e externos que permitiram aferir, de forma complementar às entrevistas semi-estruturadas, a história, a cultura e a situação das organizações em estudo.

Os dados primários foram tratados por meio de análise descritiva e análise de conteúdo. Análise documental e análise de conteúdo foram requeridas para tratamento dos dados secundários. Entre as diversas técnicas para se realizar a análise de conteúdo escolheu-se a análise categorial temática, uma vez que possibilitou a identificação de unidades de significação, isto é, dos núcleos de sentidos que constituem a comunicação. A técnica de triangulação foi exaustivamente utilizada para garantir maior confiabilidade e validade na análise dos dados, provenientes das múltiplas fontes de evidência.

\section{O Caso da Alfândega Brasileira}

A Alfândega brasileira (Aduana) existe formalmente desde 1808, antes mesmo da independência do Brasil. Em 1967, com a criação da Secretaria da Receita 
Federal (SRF), verificou-se solução de continuidade na trajetória histórica da Aduana como entidade jurídica autônoma. As suas atividades foram incorporadas no arcabouço estrutural da recém-criada SRF, definido em torno de quatro sistemas básicos: fiscalização, arrecadação, tributação e informações econômico-fiscais.

Desse modo, a Aduana brasileira deixou formalmente de existir, apesar de ser detentora de longa história institucional. No período de 1967 a 1985, as atividades aduaneiras continuaram a ser realizadas pelas unidades locais especializadas remanescentes e pelos funcionários do quadro da antiga Aduana, que foram incorporados pela SRF, mas sem um comando estratégico especializado de nível nacional. Desde 1967, portanto, os atores do comércio exterior e outras entidades internacionais passaram a se relacionar com a SRF.

A situação assim permaneceu até 1985, quando novamente se formalizou o Sistema Aduaneiro, mas em nível de divisão da SRF, sem autonomia, que passou a reunir e a ordenar as mesmas atividades e finalidades da antiga Aduana de quase duas décadas atrás. Vários fatores concorreram para a restauração da administração aduaneira (como núcleo especializado de nível estratégico nacional e núcleos especializados em nível operacional, formando um sistema que não apenas restabelece uma coordenação geral, mas, em especial, um sentido de unicidade organizacional); porém se deve dar destaque ao crescimento significativo das importações e à diversificação da pauta de exportações. Mais tarde, já em 1992, admitiu-se o uso da (re) denominação Alfândega para as unidades operacionais locais, especializadas nas atividades aduaneiras, em alguns dos portos e aeroportos brasileiros.

Vale assinalar que, além das relações que a Aduana deve manter no ambiente nacional, ela precisa atender ao contexto internacional, relacionando-se multilateralmente com outras aduanas. As aduanas do mundo todo mantêm estreito intercâmbio entre si e se articulam principalmente, embora não de forma exclusiva, por meio da Organização Mundial das Aduanas (OMA), organismo dotado de personalidade jurídica internacional e status diplomático, uma vez que congrega representantes oficiais de Nações-Estados soberanos, apesar de não ter, explicitamente, missão política.

A análise dos dados revela amplo consenso sobre algumas crenças, que parecem estar estreitamente associadas entre si, bem como com certos valores, o que sugere que elas possam constituir um sistema de crenças, em face dessa associação e interdependência. A existência do Estado, do seu papel e funções; a natureza da atividade aduaneira, da sua missão e atividades; a existência e a obrigatoriedade do ordenamento jurídico; a soberania do Estado e do ordenamento jurídico; a qualidade assimétrica do exercício do poder no relacionamento com 
a Aduana (e com o Estado) e outros pressupostos semelhantes emergem dos dados de forma consensual.

Transparece a aceitação de que é conveniente e desejável agir de acordo com a legalidade. A legalidade é pressuposto da legitimação. O Estado e a Aduana trabalham para o bem comum. A soberania do Estado e da nação deve ser preservada, a prática desleal de comércio é abominável e outras afirmações do gênero.

A historicidade da Aduana, sua corporatividade internacional e seu caráter institucional são elementos consensuais de referência freqüente, que criam a percepção de unidade do grupo, de vinculação entre si e superação das divisões políticas, funcionais e geográficas.

As manifestações culturais apresentam, em sua grande maioria, alto grau de consistência. As práticas formais e informais, tais como os eventos característicos da cultura aduaneira, são coerentes com as crenças e valores nelas reconhecidos. A ordem normativa mantém razoável imbricamento com os processos organizacionais e os elementos estruturais.

É praticamente consensual que a missão da Aduana consiste em defender e proteger a soberania e a economia nacionais e combater o contrabando e a prática desleal de comércio. A missão aduaneira seria missão do Estado em favor da nação. Essa constatação pressupõe que a Aduana se relaciona com o Estado, não com governos, como se pairasse acima das transitórias contingências políticas. De acordo com os dados, a Aduana é expressão do Estado; é o Estado em ação. Na descrição da missão surge, ainda e com expressiva intensidade, a noção de que, em essência, a Aduana defende o trabalho nacional. Observa-se nítido entendimento de que a natureza da atividade aduaneira é mais estatal-econômica do que social (stricto sensu) ou arrecadatório-tributária. Parece que os participantes do sistema aduaneiro consideram que a afirmação da sua missão é sua característica essencial mais importante, o núcleo justificador da sua existência.

Conforme sugerem Albert e Whetten (1985), os membros de determinada organização podem enfatizar ou reconhecer o que nela consideram essencial, quando se defrontam com situações em que percebem que a existência ou a identidade ou a imagem da organização está sendo ameaçada ou questionada. O episódio da extinção da Aduana em 1967, com a conseqüente incorporação das suas atividades pela SRF, e as dificuldades daí decorrentes para realizar a sua missão, bem como as reações contrárias à pretensão de se restabelecer a autonomia da Aduana, são alguns aspectos das descrições que compõem os dados analisados, que 
permitem afirmar que a percepção de um contexto adverso à sua integridade identitária é francamente compartilhada pelos membros do sistema aduaneiro.

Cabe acrescentar que as declarações sobre a missão e a natureza das atividades aduaneiras são vistas como orientadoras do modo como as outras organizações devem com ela relacionar-se e, também, como critérios para se avaliarem quais entre as suas muitas atividades são mais importantes e pertinentes à sua finalidade institucional. De outro ângulo, nas afirmações dos aspectos essenciais da identidade aduaneira coexistem crenças e valores correspondentes a duas orientações diferentes (uma, normativa; outra, utilitária), que podem estar assinalando uma situação de tensão ou um momento de transição na trajetória histórica da Aduana.

A organização aduaneira é considerada, cumulativamente, como agência estatal reguladora, normativa, controladora e repressora. Essas referências, que parecem atribuir uma classificação genérica à Aduana, revelam, entretanto, atributos de sua exclusividade e distintividade em relação a outras organizações, conforme se pôde observar nas noções compartilhadas, resumidas a seguir: (1) exclusividade da sua missão como caráter distintivo da sua identidade ("é a aduana a única que tem por missão defender a soberania e as fronteiras econômicas nacionais"); (2) historicidade ("a aduana tem uma história própria e presença ativa na história da economia brasileira"); e (3) origens ancestrais ("a origem da aduana se perde na história e está estreitamente vinculada à existência do Estado").

Ao longo da análise dos dados foi ficando evidente a importância dos institutos normativos, do pensamento político-econômico e das noções de Estado e de nação, para se descrever e compreender a construção da identidade organizacional aduaneira. As noções de nação e de Estado são consideradas em conjunto como fundamentais para a noção de Aduana. Percebe-se que os atributos caracterizadores da Aduana deitam raízes nos atributos do Estado. Muitos dos pressupostos que justificam a ação aduaneira são derivados do que se pressupõe ser o Estado.

A visão de missão aduaneira está intimamente relacionada à compreensão compartilhada sobre a natureza e o papel do Estado. O Estado é entendido como o poder máximo da nação; é a condição necessária para a afirmação da nação como país soberano. Ele é formulado e organizado na ordem jurídica e dela é o guardião. O Estado é, então, guardião da legalidade, da ordem e da independência. Há mais: o Estado cuida das fronteiras do país, da sua integridade e higidez bio-social. Ele é o gestor máximo da economia e das condições de trabalho. Deve gerir os recursos comuns para proporcionar o melhor para todos. Deve, também, agir para que as oportunidades sejam oferecidas a todos. O Estado constitui, assim, tema simbólico de grande importância na cultura aduaneira. 
Mas essa ação em defesa da economia nacional não deve ser feita a qualquer custo. Na verdade, ela está amplamente justificada no fato de que se assenta em princípios universalmente aceitos, como, por exemplo: a autodeterminação dos povos, a soberania dos países, o desenvolvimento pelo livre comércio, respeito à liberdade e à democracia, e assim por diante. Daí que se constata o entendimento compartilhado de que a Aduana não cumpre um papel doméstico menor. Ela realiza um trabalho interno e externo ao país, de um lado pontificando os princípios e valores universalmente aceitos, e, de outro, assinalando a defesa das fronteiras nacionais aos estrangeiros.

A Aduana se insere em um quadro institucional em que coabitam o nacional e o internacional, o que explica a crença em sua legitimidade. A sua autoridade, contudo, está correlacionada fortemente a uma ordem jurídica soberana. São freqüentes as referências à Constituição Federal e à leis como fonte do direito de impor conduta e exigir obediência. A noção de ordem jurídica, com um conjunto hierarquizado de leis e normas, complementa a visão de uma realidade de múltiplos interesses, ao intermediá-los, discipliná-los, protegê-los e puni-los. A Aduana exerce a sua autoridade a partir da lei; e ela é o seu principal instrumento de trabalho.

Em suma, observa-se a ocorrência de reificação no sistema de interpretação dos integrantes da organização aduaneira, resultante do entendimento da existência objetivada da Aduana, de seus papéis e da sua identidade. A Aduana tem existência, assim como existem o Estado, a nação, a soberania e outros fenômenos reificados da experiência humana.

\section{O Caso da TELEPAR ${ }^{(1)}$}

A Telecomunicações do Paraná S/A (TELEPAR) nasceu em 1963, com outra denominação. A sua trajetória encontra-se estreitamente relacionada à história das telecomunicações no Brasil, caracterizada por flutuações na forma de atuação do Estado. Com o surgimento do Conselho Nacional de Telecomunicações (CONTEL), em 1961, e, na seqüência, com a implantação da Empresa Brasileira de Telecomunicações (EMBRATEL), em 1965, inaugura-se um período centralizador de atuação governamental no setor. O processo de nacionalização das empresas desse segmento ocorre a partir da criação, em 1972, da Telecomunicações Brasileiras S/A (TELEBRÁS).

Incorporada ao sistema TELEBRÁS, em 1975, a TELEPAR atravessa as décadas de 70 e 80 construindo e expandindo a sua infra-estrutura no Estado do Paraná, onde detinha o privilégio da exclusividade na concessão de serviços. $\mathrm{Na}$ década de 90, a empresa passa a enfrentar um quadro ameaçador de mudanças 
ambientais: reforma do Estado, com base em modelo gerencial de gestão governamental; redução dos investimentos e dos gastos públicos; tendência à privatização de empresas estatais; abertura do mercado à competição, com participação de investidores internacionais; mercado e clientes mais exigentes; emergência de novos patamares de capacitação tecnológica; enfim, toda uma série de transformações contextuais decorrentes do esgotamento da capacidade de investimento e ação empresarial do Estado e da crescente inserção do Brasil na economia global.

Em meados de 1998 ocorre a privatização da TELEPAR. A análise da sua identidade organizacional, no período compreendido entre sua incorporação ao Sistema TELEBRÁS (1975) e a sua privatização (1998), traz à tona crenças e valores sobre os quais vale a pena deter-se.

A análise dos dados revela alto nível de consenso no que concerne as crenças identificadas, até o final da década de 80 . O pressuposto básico de que o sistema de telecomunicações é fundamental para a segurança nacional é altamente esposado entre os integrantes da empresa, independentemente do nível hierárquico em que se situam. Diretamente vinculadas à noção de segurança estão as crenças sobre soberania nacional, proteção dos interesses nacionais, legitimidade da ação empresarial empreendida pelo Estado.

A natureza estatal e monopolista do setor de telecomunicações e a própria especificidade do negócio propiciaram à TELEPAR condições favoráveis para o desenvolvimento de uma postura introvertida, excessivamente focada no seu processo produtivo. Desenvolveu-se uma forte cultura tecnocrática, reforçada continuamente por indicadores de desempenho técnico-operacional adotados pela holding do sistema, a TELEBRÁS.

Em conseqüência, ocorreu a sedimentação de um comportamento de autosuficiência na empresa, permeando todos os níveis hierárquicos. Valores corporativos relacionados à estabilidade no emprego e a benefícios crescentes, sem necessariamente guardar relação com o desempenho individual e organizacional, ganharam grande espaço. Clientes e mercados constituíam conceitos restritivos: quando se levantava o percentual de demanda represada todos os argumentos justificadores se apoiavam nos limites para investimentos e nas restrições tarifárias governamentais. A idéia de competitividade se restringia a metas de natureza quantitativa, estabelecidas em conjunto com a TELEBRÁS.

Em suma, o desempenho da empresa era predominantemente avaliado em relação a metas técnico-operacionais, que se constituíam em fins desejados, desconsiderando-se perspectivas e necessidades diferenciadas dos clientes, do próprio governo e da sociedade. O contexto de referência era a TELEBRÁS, quer 
visualizando possibilidades de reconhecimento e de promoção dos dirigentes, quer restringindo a noção de competitividade à disputa entre as empresas componentes do sistema.

Tal situação prevaleceu até o início dos anos 90. A partir daí, a série de transformações contextuais dessa década pressionaram a TELEPAR no sentido de mudar para poder sobreviver. As mudanças promovidas em 1992 ainda decorriam de uma visão essencialmente técnico-operacional: círculos de controle de qualidade, programa de qualidade total. Neste ponto vale registrar que a empresa, com uma longa história de Presidentes efetivos e por períodos duradouros de tempo, passou pela experiência de ter quatro presidentes temporários no curto período de dois anos - 1992 a 1994.

De acordo com depoimentos dos entrevistados, esse período de interinidade em plena circunstância de significativas transformações ambientais provocou forte abalo cultural na TELEPAR, afetando a sua identidade organizacional. Perdeuse o senso de missão e de orientação estratégica. Tanto os gerentes quanto os funcionários assinalam que já não sabiam para onde a empresa deveria seguir.

Desta forma, da inter-relacão da crise de liderança interna com fortes pressões ambientais externas emergem as condições para mudanças fundamentais na TELEPAR. Em 1996, a empresa passa por mudança de maior porte, mediante a implantação de novo modelo, intitulado Sistema de Gestão Empresarial (SGE).

A implementação do SGE resultou em redefinição da missão da empresa que passou da ênfase em segurança, soberania e proteção dos interesses nacionais para a visão de oferecer serviços de telecomunicações e multimídia para segmentos diferenciados do mercado. Clientes, acionistas e sociedade são redefinidos de forma mais ampla. Novas crenças e valores emergem na empresa. Ética, orientação estratégica, desterritorialização/globalização, qualidade, satisfação do cliente, competitividade em sentido menos restrito, rentabilidade e capacitação profissional passam a conviver com valores anteriores como hierarquia, corporativismo e empregabilidade.

Em síntese, verificou-se: 1) a transformação da razão de ser da TELEPAR (o que é essencial) a partir do novo caráter institucional de sua missão; 2) a mudança da sua situação exclusiva como empresa estatal monopolista do setor de telecomunicações do Paraná, obrigando-a a redefinir o seu papel social (o que é distintivo); e 3) a modificação da sua representação na ordem institucional (o que é duradouro).

No período de 1996 a 1998, a TELEPAR debateu-se para definir o seu novo papel na nova ordem institucional vigente. $O$ conflito entre novos e antigos valo- 
res constituía o foco e o lugar das interações sociais dos seus membros, nos diversos níveis hierárquicos. Infelizmente esse estudo teve que se encerrar pouco antes dos eventos que culminaram na sua privatização, em meados de 1998. Tal fato claramente delimitou o campo de visão dos pesquisadores sobre a nova identidade organizacional em processo de formação na empresa de telecomunicações resultante.

\section{Considerações Finais}

Os dois casos analisados constituem exemplos interessantes no estudo da identidade organizacional. O tipo de leitura do ambiente circundante por parte dos membros organizacionais revelou-se fundamentalmente ligado à trajetória de cada organização e à cultura organizacional. Tanto no caso de manutenção da identidade organizacional como no caso de mudança, o contexto institucional de referência desempenhou papel relevante, como se pode observar na análise precedente.

No caso da Alfândega brasileira, a sua incorporação pela recém-criada Secretaria da Receita Federal, em 1967, não obliterou a sua identidade organizacional aduaneira, como seria de se esperar. Tal constatação remete à importância da influência do sistema aduaneiro internacional, que coabita com a soberana ordem jurídica nacional (caracterizando o contexto institucional de referência entre-tipos, nacional e internacional, da Alfândega brasileira), sobre as crenças e valores da Aduana. Os artefatos e os significados compartilhados acabaram por manter a identidade organizacional de uma organização que, em última instância, havia deixado de existir em termos da sua configuração anterior. Não se deve perder de vista que se passaram 25 anos desde o momento da sua incorporação pela Secretaria da Receita Federal até a sua (re)denominação como Alfândega. Se o contexto institucional de referência da Secretaria da Receita Federal passasse a ser também o da Aduana, em tão longo período de tempo, seguramente teria ocorrido a reformulação da identidade organizacional da Aduana, o que não se verificou.

No que concerne à TELEPAR, parece ter sido a conjunção de fatores internos e externos que ocasionou a sua crise de identidade. No período de 1975 até os primeiros anos da década de 90, o contexto institucional de referência da empresa circunscrevia-se, mais do que ao Estado do Paraná, ao sistema TELEBRÁS. Crenças sobre o papel e a razão de ser das telecomunicações como instrumento de segurança e soberania nacionais, aliadas a valores como competitividade téc- 
nico-operacional restrita, corporativismo, hierarquia e manutenção do emprego impediram que a TELEPAR pudesse avaliar adequadamente a extensão e profundidade das mudanças ambientais decorrentes da globalização da economia e dos mercados, e do esgotamento da capacidade de investimento e ação empresarial do Estado brasileiro. Tais circunstâncias, em adição ao período de interinidade das lideranças estratégicas da empresa, geraram uma situação de crise que acabou afetando a sua identidade organizacional. Ao invés de modificações contínuas e incrementais que poderiam ter atenuado a situação e propiciado ajustes graduais na identidade organizacional, a mudança acabou se configurando como de natureza fundamental.

Os dois casos analisados permitem que se verifique mais de perto a definição de identidade organizacional proposta por Albert e Whetten (1985). Entre os três componentes da definição desses autores, o pressuposto de que a identidade organizacional é duradoura vem sendo considerado o mais discutível, em face do acelerado ritmo de mudanças ambientais nesses tempos de globalização. Argumenta-se que as rápidas e freqüentes transformações ambientais requerem correspondentes mudanças nas organizações contemporâneas, implicando modificações substanciais não apenas dos objetivos e estratégias mas, até mesmo, da missão. A despeito do argumento ser razoável, não se pode incorrer no equívoco de generalização fácil para todos os tipos de organizações.

No caso do presente estudo parece evidente que a Alfândega é um tipo de organização menos sujeita a pressões ambientais para mudanças significativas do que a TELEPAR. Assim, a idéia de duradouro parece ser sensível não apenas ao ritmo e à extensão das transformações ambientais, mas, também, ao tipo de organização, ao ramo de atividade em que está inserida e ao nível de competição no segmento em que se inclui. Talvez seja o caso dos pesquisadores em estudos organizacionais aumentarem a sua atenção para os conceitos de setor, ramo e campo organizacional.

\section{Nota}

${ }^{1}$ Os autores agradecem a Claudia Ramos de Oliveira por possibilitar o uso de dados de sua pesquisa na Telecomunicações do Paraná S/A. 
Referências Bibliográficas

ADLER, A.

A ciência da natureza humana. 4. ed. São Paulo: Cia. Editora Nacional, 1957.

\section{ALBERT, S.;}

WHETTEN, D. A.

Organizational identity. In: CUMMINGS, L. L.; STAW, B. M. (Eds.). Research in organizational behavior. Greenwich: Jay Press, 1985. p. 263-295.

\section{ALLAIRE, Y.;} FIRSIROTU, M.

Theories of organizational culture. Organization Studies, v. 15, n. 3, p. 193-226, 1984.

\section{ALLPORT, G. W.}

Personalidade: padrões edesenvolvimento. São Paulo: EDUSP, 1973.

\section{ALVESSON, M.}

Talking in organizations: managing identity and impressions in an advertising agency. Organization Studies, v. 15, n. 4, p. 535-563, 1994.

ALVESSON, M.;

BERG, P. O.

Corporate culture and organizational symbolism.
New York: Walter de Gruyter, 1992.

BERGER, P. L.;

LUCKMANN, T.

The social construction of reality: a treatise in the sociology of knowledge. New York: Doubleday Anchor Books, 1967.

CALDAS, M. P.;

WOOD JR., T.

Identidade organizacional. Revista de Administração de Empresas, v. 37, n. 1, p. 6-17, jan./mar. 1997.

CHANLAT, J.-F.

Por uma antropologia da condição humana nas organizações. In: . (Coord.). $\mathbf{O}$ indivíduo na organização: dimensões esquecidas. São Paulo: Atlas, 1992. p. 21-45

DEJOURS, C.

Uma nova visão do sofrimento humano nas organizações. In: CHANLAT, J.-F. (Coord.). O indivíduo na organização: dimensões esquecidas. São Paulo: Atlas, 1992.p. 149-173. 
DUTTON, J. E.;

DUKERICH, J. M.;

HARQUAIL, C. V.

Organizational images and member identification. Administrative Science Quarterly, v. 39, p. 239-263, 1994.

ELSBACH, K. D.

Managing organizational legitimacy in the California cattle industry: the construction and effectiveness of verbal accounts. Administrative Science Quarterly, v. 39, p. 57-88, 1994.

ELSBACH, K. D.;

KRAMER, R. M.

Members' responses to organizational identity. Administrative Science Quarterly, v. 41, p. 442-476, 1996.

\section{ENGELS, J. F.;}

BLACKWELL, R. D.;

MINIARD, P. W.

Consumer behavior. 8. ed. New York: The Dryden Press, 1995.

ENZ, C.

The role of value congruity in interorganizational power. Administrative Science Quarterly, v. 33, n. 2, p. 284-304, June 1988.
ERIKSON, E.

Identidade, juventude e crise. Rio de Janeiro: Zahar Editores, 1976.

FILLOUX, J.-C.

A personalidade. São Paulo: Difusão Européia do Livro, 1960.

FIOL, C. M.

Managing culture as a competitive resource: an identity-based view of sustainable competitive advantage. Journal of Management, v. 17, n. 1, p. 191-211, 1991.

FREITAG, B.

Piaget e a filosofia. São Paulo: Editora UNESP, 1991.

FREUD, S.

El yo y el ello. In: Obras completas. Madrid: Editorial Biblioteca Nueva, 1974. tomo VII.

A dissecção da personalidade psíquica. In: Obras psicológicas completas de Freud. Rio de Janeiro: Imago, 1976. v. XXII.

\section{GEERTZ, C.}

A interpretação das culturas. Rio de Janeiro: Guanabara Koogan, 1989. 
GIOIA, D.;

THOMAS, J.

Identity, image and issue interpretation: sensemaking during a strategic change in academia. Administrative Science Quarterly, v. 41, p. 370403, 1996.

GOFFMAN, E.

A representação do eu na vida cotidiana. Petrópolis: Vozes, 1985.

\section{HATCH, M. J.}

Organization theory - modern, symbolic and postmodern perspectives. New York: Oxford University Press, 1997.

HININGS, C. R.;

GREENWOOD, R.

The dynamics of strategic change. New York: Basil Blackwell, 1989.

HOLMER-NADESAN, M.

Organizational identity and space of action. Organizational Studies, v. 17, n. 1, p. 49-81, 1996.

JUNG, C. G.

AION - estudos sobre o simbolismo do si-mesmo. Petrópolis: Vozes, 1988.
LACAN, J.

$\mathrm{O}$ eu na teoria de Freud e na técnica da psicanálise. In: $\mathbf{O}$ seminário. Rio de Janeiro: Zahar Editores, 1985. livro 2.

LYRA, C. E.

A metáfora da prisão psíquica. Curitiba: UFPR, 1997.

MACHADO-DA-SILVA, C. L.; FONSECA, V. S. DA;

FERNANDES, B. H. R. Um modelo e quatro ilustrações: em análise a mudança nas organizações. In: XXIII ENCONTRO ANUAL DA ANPAD (1999: Foz do Iguaçu). Anais Eletrônicos... ANPAD: Foz do Iguaçu, 1999.

Cognição e institucionalização na dinâmica da mudança em organizações. In: RODRIGUES, S. B.; CUNHA, M. P. (Orgs.). Estudos organizacionais: novas perspectivas na administração de empresas - uma coletânea luso-brasileira. São Paulo: Iglu, 2000. p. 123-150.

MARTIN, J.

Culture in organizations: three perspectives. New York: Oxford University Press, 1992.

MEAD, G. H.

Espiritu, persona y sociedad: desd el punto de vista del condutismo social. Buenos Aires: Editorial Paidos, 1953. 
MORGAN, G.

Imagens da organização. São Paulo: Atlas, 1996.

OLIVEIRA, C. R.

Reação cultural e política à mudança estratégica: o caso da TELEPAR. Curitiba, 1998. Dissertação (Mestrado em Administração) - Centro de Pesquisa e Pós-Graduação em Administração, Universidade Federal do Paraná.

PAGÈS, M. et al.

O poder nas organizações. São Paulo: Atlas, 1993.

RODRIGUES, S. B.

Cultura corporativa e identidade: desinstitucionalização em empresa de telecomunicações brasileira. Revista de Administração Contemporânea, v. 1, n. 2, p. 4572, maio/ago. 1997.

SACKMANN, S.

Cultures and subcultures: an analysis of organizational knowledge. Administrative Science Quarterly, v. 37, p. 140161, Mar. 1992.

SCHEIN, E.

Organizational culture and leadership. San Francisco: Jossey-Bass, 1991.

SMIRCICH, L.

Concepts of culture and organizational analysis. Administrative Science Quarterly, v.28,n.3, p. 339-358, Sept. 1983.

TRICE, H. M.;

BEYER, J. M.

The cultures of work organizations. New York: Prentice-Hall, 1993.

TURNER, B. A.

Sociological aspects of organizational symbolism. Organizational Studies, v. 7, $\mathrm{n}$. 12, p. 101-115, 1986. 